\title{
RESEARCH
}

Open Access

\section{Risk of suicide and accidental deaths among elderly patients with cognitive impairment}

\author{
Ji Hyun An ${ }^{1}$, Kyung Eun Lee ${ }^{1}$, Hong Jin Jeon ${ }^{1}$, Sang Joon Son ${ }^{2}$, Sung Yoon Kim³ and Jin Pyo Hong ${ }^{1 *}$
}

\begin{abstract}
Background: The leading causes of death among the elderly with cognitive impairment are unknown. This study aims to estimate the suicide and accidental death rates on the basis of a clinical case registry of patients diagnosed with cognitive impairment.
\end{abstract}

Methods: The target sample consisted of 10,169 patients diagnosed with dementia or mild cognitive impairment (MCI), who were evaluated at the Clinical Research Center for Dementia of Korea (CREDOS) from January 2005 to December 2013. Information about whether the patients had died from suicide or in any kind of accident by December 31, 2016, was obtained from the database of the National Statistical Office (NSO). The standardized mortality ratio (SMR) and Cox-regression analysis were performed for evaluating the risk of suicide and accidental death as identified by the ICD-10.

Results: The average of the Clinical Dementia Rating Scale (CDR) score (0.68 vs 0.93) was lower, and the age at the time of study registration (71.42 vs 75.68 years) was younger in the suicidal death group, as compared to the accidental death group. The overall SMR for accidental death in cognitively impaired patients $(1.44,95 \% \mathrm{Cl} 1.22-1$. 71) was significantly higher than the general population. Later onset $(1.43,95 \% \mathrm{Cl} 1.20-1.71)$ and older age (2.21, $95 \% \mathrm{Cl} 1.04-4.68)$ increased the risk of accidental death in cognitively impaired patients. According to the dementia subtypes, the SMR for accidental death was higher in both Alzheimer's disease $(1.72,95 \% \mathrm{Cl} 1.36-2.14)$ and vascular dementia (2.14, 95\% Cl 1.27-3.38). Additionally, the SMR for accidental death showed an increasing tendency as the CDR score increased (mild 1.80, 95\% Cl 1.32-2.42, moderate 1.86, 95\% Cl 1.07-3.03, severe 3.32, 95\% Cl 1.08-7.76). Unemployment increased the risks of both suicide $(3.71,95 \% \mathrm{Cl} 1.54-8.95)$ and accidental death $(2.09,95 \% \mathrm{Cl} 1.20-$ 3.63).

Conclusions: Among people with cognitive impairment, the risk of death by suicide did not increase, whereas that of accidental death increased significantly. Preventive strategies for premature mortality in those with cognitive impairment should be implemented from the early stages and should include careful evaluation of the individual risk factors for each type of death.

Keywords: Cognitive impairment, Dementia, Suicide, Accidental death, Elderly

\footnotetext{
* Correspondence: suhurhong@gmail.com

${ }^{1}$ Department of Psychiatry, Samsung Medical Center, Sungkyunkwan

University School of Medicine, 81 Irwon-ro Gangnam-gu, Seoul 06351, South

Korea

Full list of author information is available at the end of the article
}

(c) The Author(s). 2019 Open Access This article is distributed under the terms of the Creative Commons Attribution 4.0 International License (http://creativecommons.org/licenses/by/4.0/), which permits unrestricted use, distribution, and reproduction in any medium, provided you give appropriate credit to the original author(s) and the source, provide a link to the Creative Commons license, and indicate if changes were made. The Creative Commons Public Domain Dedication waiver (http://creativecommons.org/publicdomain/zero/1.0/) applies to the data made available in this article, unless otherwise stated. 


\section{Introduction}

Cognitive impairment is prevalent in late life and may impact on mortality of the elderly. The World Health Organization (WHO) estimates that the number of people over the age of 60 will be around 2 billion in 2050, while the number of dementia patients is expected to rise rapidly along with the aging population [1]. Current data suggest that the prevalence of age-adjusted dementia in 65 -year-olds is over 5\% [2], and their mortality is 3.3-6.0 times higher than that of the general population [3].

As South Korea is now an aged society, the concept of "dying well" becomes more important; thus, the major causes of death among the elderly have been receiving greater attention. Apart from medical comorbidities, suicide and accidental death are also prevalent in the elderly, which suggests that their prevention is a priority in terms of public health.

Suicide is one of the most common causes of death in elderly people, with its prevalence ranging from 18 to $20 \%$ [4-6]. Additionally, most mental disorders are known to be associated with increased mortality because of suicide [7]. However, there is a lack of understanding of suicide death among those with cognitive impairment such as dementia or MCI. Death by suicide is known to be infrequent in the advanced stages of cognitive impairment, but some reports have shown a higher risk of suicide during the early stages of cognitive impairment $[8,9]$ when their insight and the ability to plan suicide are intact. Although there are reports that show depressive symptoms are linked to suicide in patients with cognitive impairment [10-13], little is yet known about the relationship between cognitive impairment itself and suicide.

Accidents are also one of the leading causes of all deaths, but have not been of great interest in terms of their relationship with psychiatric disorders. A recent study reported that all mental disorders, including cognitive impairment, substantially increased the risk of accidental death [14]. However, there is hardly much known about the specific risk factors of accidental death and the relationship between severities of cognitive impairment and accidental death.

The aim of this study was to investigate whether the mortality risks due to suicide and accidental death increase and to investigate the causes of death-related factors among patients with cognitive impairment. We also compared the risks of each cause of death in those with cognitive impairment against in those of the general population, where we hypothesized that the rate of accidental death rather than suicide would be higher among patients with cognitive impairment.

\section{Methods}

\section{Data sources}

The target sample was recruited from the Clinical Research Center for Dementia of Korea (CREDOS) from
January 2005 to December 2013. The CREDOS is a clinical research group consisting of board-certified neurologists, psychiatrists, and neuropsychologists, who evaluate the multi-hospital-based longitudinal registry of dementia patients, which is the largest clinical dementia cohort in Korea. All CREDOS patients who visited outpatient clinics in 56 participating hospitals for their cognitive impairment were comprehensively evaluated with standardized neuropsychiatric protocol, as described elsewhere [15].

Exclusion criteria for the CREDOS study were (1) history of significant hearing or visual impairment rendering participation in the interview difficult; (2) neurological disorders (e.g., territorial infarction, intracranial hemorrhage brain tumor, hydrocephalus, multiple sclerosis, Parkinson's disease, or Huntington's disease); (3) major psychiatric disorders (e.g., schizophrenia, intellectual disability, current episodes of major depressive disorder, or mania); and (4) physical illnesses that could interfere with the clinical study (e.g., severe cardiorespiratory disease, fulminant hepatic or renal disease, uncontrolled diabetes, or malignancy). This was because such patients had difficulty in receiving the neuropsychiatric interviews or in making periodic visits due to poor medical conditions. A total of $14,013 \mathrm{pa}-$ tients with cognitive impairment who were eligible to enroll in the CREDOS study were selected. Of these, 2044 patients with uncertain diagnosis of cognitive impairment and 1800 healthy subjects with subjective memory impairment were excluded. Finally, a total of 10,169 patients with cognitive impairment were selected for our analysis (Fig. 1). The cohort patients contributed a total of 65,255 person-years, and the mean (SD) and median follow-up time were 6.42 (2.36) and 6.77 years, respectively.

The causes of death of subjects were verified by linking the CREDOS data to the Korean National Statistical Office (NSO) death index database [5] through a unique national identification number assigned to every South Korean citizen since December 31, 2016. Suicide death was indicated by the ICD-10 code as X60-X84 (intentional self-harm), and accidental death was indicated by the ICD-10 codes as W00-W19 (falls), V01-V99 (transport accidents), and X40-X49 (accidental poisoning).

\section{Measures \\ Diagnosis and classifications of incident cognitive impairment}

Patients were diagnosed with cognitive impairment according to the National Institute of Neurological and Communicative Disorders and Stroke, and the AD and Related Disorders Association (NINCDS-ADRDA) [16]; National Institute of Neurological Disorders and Stroke, and Association Internationale pour la Recherche et 


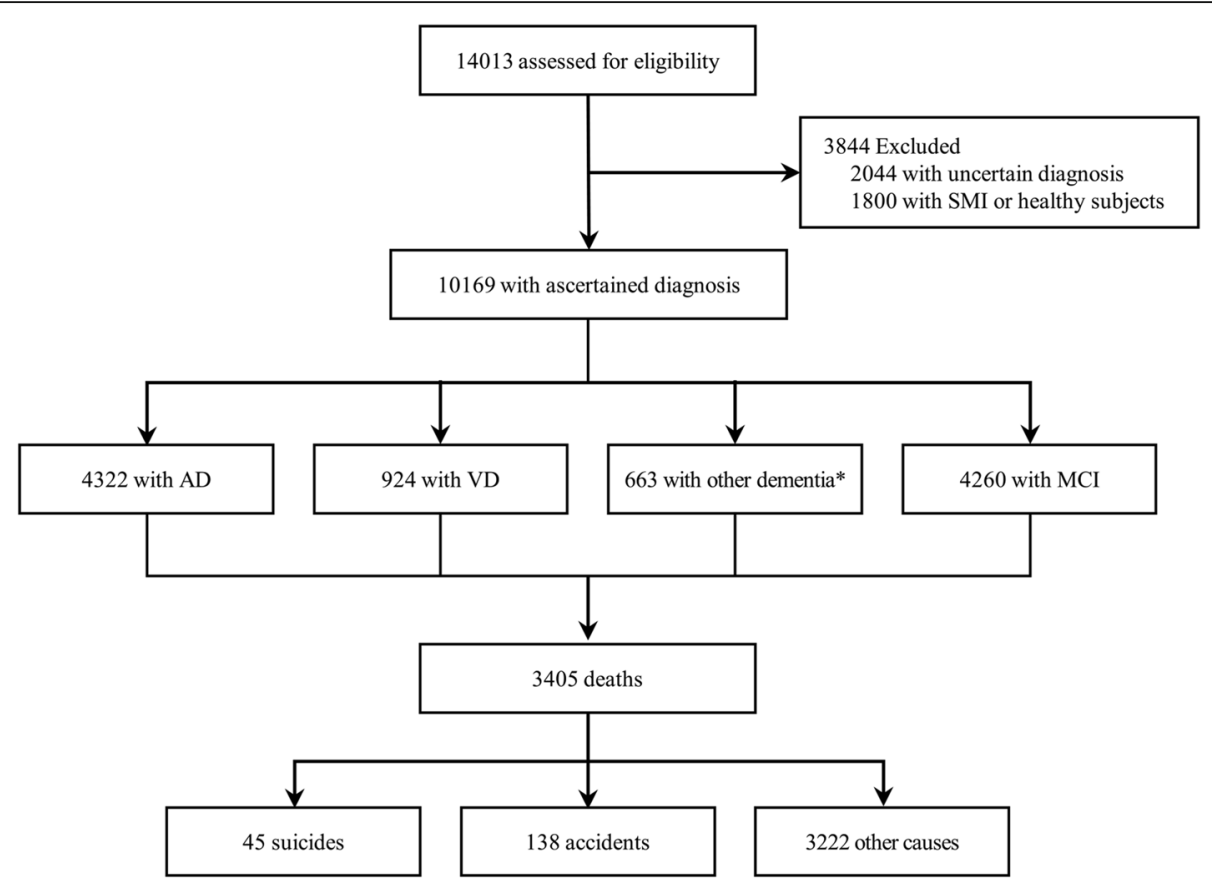

Fig. 1 Flow and outcomes of the study patients, 2005 through 2016. AD Alzheimer's disease, VD vascular dementia, MCI mild cognitive impairment, SMl subject memory impairment. * Other dementia: dementia with Lewy bodies (DLB), frontotemporal dementia (FTD), and unspecified dementia

I'Enseignement en Neurosciences (NINDS-AIREN) [17]; Modified Hachinski Ischaemic Score (MHIS) [18]; McKeith criteria for dementia with Lewy bodies (DLB) [19]; the Lund and Manchester criteria for frontotemporal dementia (FTD) [20]; and the Diagnostic and Statistical Manual of Mental Disorders, Fourth edition (DSM-IV) [21]. For MCI, the criteria in the CREDOS study were as follows: (1) presence of memory-related complaints; (2) intact functioning in activities of daily living (ADL); (3) objective cognitive impairment (at least 1.0 standard deviation [SD] below ageand education-adjusted norms) in more than one cognitive domain on standardized neuropsychological testing [22]; (4) Clinical Dementia Rating (CDR) [23] of 0.5; and (5) considered not demented according to the Diagnostic and Statistical Manual of Mental Disorders (DSM)-IV criteria.

Patient's sociodemographic variables included sex, age, occupational status, educational level, and duration to death after diagnosis of cognitive impairment and were collected at the time of registration. The ages of patients at the time of registration was designated as their age on the date on which the clinical neuropsychological evaluation was first made for incidents of cognitive impairment. Each participant was entitled to only one major type of cognitive disorder in this study.

\section{Clinical evaluation}

All study patients underwent a complete medical interview and neuropsychiatric evaluation. Clinical assessments related to the severity of cognitive impairment, including the Clinical Dementia Rating Scale (CDR) and the Korean Mini-Mental State Examination (K-MMSE) [24], were measured by board-certified neuropsychiatrists in face-to-face interviews of each patient. Reliable caregivers of each patient were made to complete several caregiver questionnaires, such as Seoul Instrumental ADL (S-IADL) [25] and the Korean version of the Neuropsychiatric Inventory (K-NPI) [26].

This study was approved by the Institutional Review Board of Samsung Medical Center in Seoul, Korea (IRB No. SMC 2018-08-136). All study patients were fully informed of the aims and methods of the study, and written consent was obtained from all patients.

\section{Data analysis}

The standardized morality ratio (SMR) was computed as the ratio of the observed number of suicides and accidental deaths in those with cognitive impairment to the expected number of each type of deaths, based on the age-, sex-, and time-specific incidence rates among the general Korean population, in the period between January 2005 and December 2016.

The sociodemographic characteristics and findings of the clinical assessments were compared using a Pearson chi-squared test for categorical variables, and Student's $t$ test or Mann-Whitney $U$ test for continuous variables. Furthermore, Cox proportional hazards regression 
analyses were performed to identify the mortality risks of each type of death with the selected variables of cognitive impairment. Patients' characteristics and clinical variables that were previously demonstrated in univariate analyses to be significant risk factors of each type of death were entered into the multivariate models. All models were initially adjusted for age and sex. We also performed a separate multivariate analysis for the MCI group in order to identify the risk factors of each type of death.

All statistical analyses were performed with the Statistical Analysis System (SAS, version 9.4, SAS Institute Inc., Cary, NC, USA), with a statistical significance cutoff at an alpha level of 0.05 .

\section{Results}

Demographic characteristics associated with suicide and accidental death in elderly patients with cognitive impairment

The demographics and clinical factors of the study patients at registry from January 2005 to December 2013 are summarized according to the type of death in Table 1. For a 12-year-follow-up period, a total of 3405 deaths were observed among 10,169 patients. Among these, 45 patients $(0.44 \%)$ died by suicide and 138 (1.36\%) died due to accidents. The mean duration between the study registration and death was shorter for suicide deaths $(2.80 \pm 2.28$ year $)$ than accidental deaths (3.74 \pm 2.45 year), with a statistical significance of $p=$ 0.024 .

Around half of the accidental death patients were male (52.9\%). Compared to the accidental death group, those in the suicidal death group were younger at the time of study registration and tended to have fewer symptoms of cognitive impairment, which were measured using CDR and S-IADL. The suicidal death group also demonstrated a lesser number of years of education (4.22 vs
5.41 years) and were more frequently employed (24.4 vs $16.7 \%$ ) than the accidental death group.

\section{Comparison of SMR for suicide and accidental death in elderly patients with cognitive impairment}

Table 2 shows the SMR for suicide and accidental death on the basis of gender, age, and type of impairment at the time of study registration. The overall SMR calculated in patients with cognitive impairment was 0.98 (95\% CI $0.71-1.31$,) for suicide deaths and 1.44 (95\% CI 1.22-1.71) for accidental deaths. Both male (1.71, 95\% $\mathrm{CI}=1.34-2.15)$ and female $(1.36,95 \%$ CI $1.05-1.73)$ patients demonstrated higher SMR for accidental deaths. There was no gender difference for suicide deaths. The SMR for accidental deaths was significantly higher when a patient's age at the time of registration was older (1.43, 95\% CI 1.20-1.71).

Based on the type of cognitive impairment, the SMR for accidental deaths was significantly higher for both Alzheimer's disease (1.72, 95\% CI 1.36-2.14) and vascular dementia (2.14, 95\% CI 1.27-3.38).

The SMR according to the severity of cognitive impairment, which was measured using CDR, is shown in Fig. 2. The SMR for suicide showed a decreasing tendency as the CDR scores increased (very mild 1.04, 95\% CI $0.71-1.48$, mild 0.98 , 95\% CI $0.49-1.75$, moderate $0.54,95 \%$ CI $0.07-1.97)$; however, it was not statistically significant. On the other hand, the SMR for accidental death showed an increasing tendency as the CDR scores increased (mild 1.80, 95\% CI 1.32-2.42, moderate 1.86, 95\% CI 1.07-3.03, severe 3.32, 95\% CI 1.08-7.76).

\section{Clinical variables associated with suicide and accidental death in elderly patients with cognitive impairment} Table 3 summarizes the results of the Cox regression of the clinical variables associated with suicide and accidental death in dementia and MCI patients.

Table 1 Demographic and clinical characteristics of study patients at the time of CREDOS registration

\begin{tabular}{|c|c|c|c|c|c|}
\hline Characteristics & Suicide death & Accidental death & Other & $p$ & Post hoc \\
\hline Male sex, $N(\%)$ & $19(42.2)$ & $73(52.9)$ & $3383(33.9)$ & $<0.000^{* * *}$ & Accidental death $>$ others \\
\hline Age at time of registration, mean (SD), years & $71.42(7.60)$ & $75.68(7.54)$ & $72.10(8.41)$ & $<0.000^{* * *}$ & Accidental death > suicide death, others \\
\hline Occupational status, N (\%) & $11(24.4)$ & $23(16.7)$ & $1579(15.8)$ & 0.575 & \\
\hline Education, mean (SD), years & $4.22(2.50)$ & $5.41(2.82)$ & $5.14(2.81)$ & $0.048^{*}$ & Accidental death > suicide death \\
\hline CDR score, mean (SD) & $0.68(0.37)$ & $0.93(0.62)$ & $0.79(0.54)$ & $0.004^{* *}$ & Accidental death > Suicide death, others \\
\hline K-MMSE score, mean (SD) & $21.29(5.49)$ & $20.03(5.23)$ & $21.76(6.02)$ & $0.009^{* *}$ & Others > accidental death \\
\hline S-IADL score, mean (SD) & $12.29(10.23)$ & $17.95(12.07)$ & $13.78(11.49)$ & $<0.000^{* * *}$ & Accidental death > suicide death, others \\
\hline K-NPI score, mean (SD) & $13.00(13.90)$ & $15.21(20.14)$ & $11.88(16.03)$ & $0.043^{*}$ & Accidental death $>$ others \\
\hline
\end{tabular}

Bonferroni correction for multiple comparisons

Abbreviation: CDR Clinical Dementia Rating Scale, CREDOS Clinical Research Center for Dementia of Korea, K-MMSE Korean Mini-Mental State Examination, SD standard deviation, S-IADL Seoul Instrumental Activity of Daily Living, K-NPI Korean version of Neuropsychiatric Inventory

${ }^{*} p<0.05,{ }^{* *} p<0.01,{ }^{* * *} p<0.001$ 
Table 2 Comparison of SMR for suicide and accidental death according to gender, age, and type of cognitive impairment at the time of CREDOS registration

\begin{tabular}{|c|c|c|c|c|c|c|c|}
\hline \multirow[t]{2}{*}{ Variables } & \multirow[t]{2}{*}{ PYAR } & \multicolumn{3}{|l|}{ Suicide death } & \multicolumn{3}{|l|}{ Accidental death } \\
\hline & & $\begin{array}{l}\text { Observed death, } \\
N\end{array}$ & $\begin{array}{l}\text { Expected death, } \\
N\end{array}$ & SMR $(95 \% \mathrm{Cl})$ & $\begin{array}{l}\text { Observed death, } \\
N\end{array}$ & $\begin{array}{l}\text { Expected death, } \\
N\end{array}$ & SMR $(95 \% \mathrm{Cl})$ \\
\hline All $(N=10,169)$ & 65,255 & 45 & 46.01 & $\begin{array}{l}0.98(0.71- \\
1.31)\end{array}$ & 138 & 95.61 & $\begin{array}{l}1.44(1.22- \\
1.71)\end{array}$ \\
\hline \multicolumn{8}{|l|}{ Gender } \\
\hline Men $(N=3475)$ & 20,429 & 19 & 24.06 & $\begin{array}{l}0.79(0.48- \\
1.23)\end{array}$ & 73 & 42.71 & $\begin{array}{l}1.71(1.34- \\
2.15)\end{array}$ \\
\hline Women $(N=6694)$ & 44,826 & 26 & 18.34 & $\begin{array}{l}1.42(0.93- \\
2.08)\end{array}$ & 65 & 47.76 & $\begin{array}{l}1.36(1.05- \\
1.73)\end{array}$ \\
\hline \multicolumn{8}{|l|}{ Age at time of registration } \\
\hline$<65$ years $(N=1721)$ & 12,211 & 5 & 4.96 & $\begin{array}{l}1.01(0.33- \\
2.35)\end{array}$ & 10 & 6.34 & $\begin{array}{l}1.58(0.76- \\
2.90)\end{array}$ \\
\hline 65 years $\leq(N=8447)$ & 53,034 & 40 & 41.03 & $\begin{array}{l}0.97(0.70- \\
1.33)\end{array}$ & 128 & 89.26 & $\begin{array}{l}1.43(1.20- \\
1.71)\end{array}$ \\
\hline \multicolumn{8}{|l|}{ Type of cognitive impairment } \\
\hline Alzheimer's dementia $(N=4322)$ & 26,291 & 21 & 20.23 & $\begin{array}{l}1.04(0.64- \\
1.59)\end{array}$ & 78 & 45.46 & $\begin{array}{l}1.72(1.36- \\
2.14)\end{array}$ \\
\hline Vascular dementia $(N=924)$ & 5320 & 3 & 3.97 & $\begin{array}{l}0.75(0.16- \\
2.21)\end{array}$ & 18 & 8.41 & $\begin{array}{l}2.14(1.27- \\
3.38)\end{array}$ \\
\hline Other dementia* $(N=663)$ & 4070 & 3 & 2.43 & $\begin{array}{l}1.23(0.67- \\
1.47)\end{array}$ & 4 & 4.46 & $\begin{array}{l}0.90(0.24- \\
2.30)\end{array}$ \\
\hline $\begin{array}{l}\text { Mild cognitive impairment }(N= \\
4260)\end{array}$ & 29,574 & 18 & 19.36 & $\begin{array}{l}0.93(0.55- \\
1.47)\end{array}$ & 38 & 37.28 & $\begin{array}{l}1.02(0.72- \\
1.40)\end{array}$ \\
\hline
\end{tabular}

Abbreviation: CI confidence interval, CREDOS Clinical Research Center for Dementia of Korea, PYAR person-years at risk, SMR standardized mortality ratio *Other dementia: dementia with Lewy bodies (DLB), frontotemporal dementia (FTD), and unspecified dementia

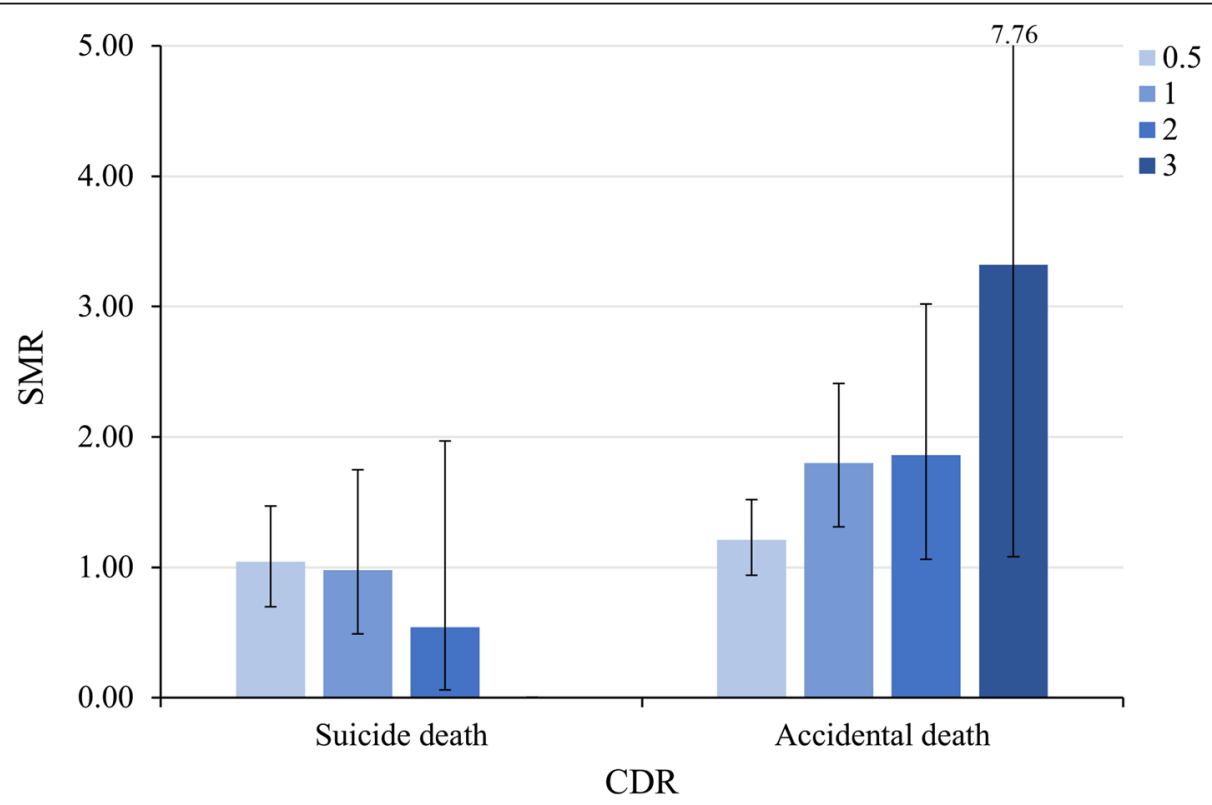

Fig. 2 Comparison of SMRs for suicide and accidental death according to the severity of cognitive impairment measured in CDR. CDR Clinical Dementia Rating Scale, SMR standardized mortality ratio 
Table 3 Univariate and multivariate Cox proportional hazards models for variables associated with suicide and accidental death in study patients

\begin{tabular}{|c|c|c|c|c|}
\hline \multirow[t]{3}{*}{ Variable } & \multicolumn{4}{|l|}{ HR $(95 \% \mathrm{Cl})$} \\
\hline & \multicolumn{2}{|l|}{ Suicide death } & \multicolumn{2}{|l|}{ Accidental death } \\
\hline & Univariate & Multivariate & Univariate & Multivariate \\
\hline \multicolumn{5}{|l|}{ Total dementia } \\
\hline 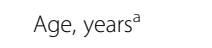 & $4.24(0.58-31.28)$ & $5.14(0.69-38.50)$ & $2.31(1.07-4.99)^{\dagger}$ & $2.21(1.04-4.68)^{\dagger}$ \\
\hline \multicolumn{5}{|c|}{ Occupational status } \\
\hline Yes & Reference & Reference & Reference & Reference \\
\hline No & $2.76(1.16-6.51)^{\dagger}$ & $3.71(1.54-8.95)^{\dagger}$ & $2.06(1.19-3.59)^{\dagger}$ & $2.09(1.20-3.63)^{\dagger}$ \\
\hline Education, years $^{\mathrm{a}}$ & $0.96(0.88-1.03)$ & $0.96(0.89-1.03)$ & $1.00(0.97-1.05)$ & $1.01(0.98-1.05)$ \\
\hline \multicolumn{5}{|c|}{ Clinical neuropsychiatric scores } \\
\hline K-MMSE ${ }^{b}$ & $1.02(0.84-1.06)$ & $1.01(0.95-1.09)$ & $1.00(0.96-1.05)$ & $0.99(0.96-1.03)$ \\
\hline S-IADL $L^{a}$ & $0.98(0.95-1.03)$ & $0.99(0.95-1.02)$ & $1.02(1.01-1.04)^{\dagger}$ & $1.06(1.01-1.08)^{\dagger}$ \\
\hline $\mathrm{K}-\mathrm{NPl}{ }^{\mathrm{a}}$ & $1.88(0.86-4.15)$ & $1.01(0.99-1.03)$ & $1.01(1.00-1.02)^{\dagger}$ & $1.00(0.99-1.01)$ \\
\hline \multicolumn{5}{|c|}{ Mild cognitive impairment } \\
\hline 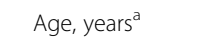 & $1.07(0.03-3.27)$ & $1.07(0.35-3.25)$ & $3.81(1.02-12.74)^{\dagger}$ & $3.63(1.12-11.79)^{\dagger}$ \\
\hline \multicolumn{5}{|c|}{ Occupational status } \\
\hline Yes & reference & reference & reference & reference \\
\hline No & $0.99(0.13-3.21)$ & $0.96(0.32-2.90)$ & $0.79(0.33-1.89)$ & $0.76(0.34-1.73)$ \\
\hline Education, years ${ }^{\mathrm{a}}$ & $0.90(0.82-0.99)^{\dagger}$ & $0.90(0.81-0.99)^{\dagger}$ & $1.07(1.01-1.13)^{\dagger}$ & $1.01(1.00-1.13)^{\dagger}$ \\
\hline \multicolumn{5}{|c|}{ Clinical neuropsychiatric scores } \\
\hline K-MMSE ${ }^{\mathrm{b}}$ & $1.04(0.88-1.20)$ & $1.04(0.91-1.19)$ & $1.03(1.00-1.15)^{\dagger}$ & $1.05(0.95-1.15)$ \\
\hline S-IADL ${ }^{a}$ & $0.99(0.89-1.10)$ & $0.97(0.87-1.07)$ & $1.10(1.02-1.14)^{\dagger}$ & $1.08(1.03-1.12)^{\dagger}$ \\
\hline $\mathrm{K}-\left.\mathrm{NPl}\right|^{\mathrm{a}}$ & $0.94(0.91-1.05)$ & $0.99(0.94-1.05)$ & $1.01(1.00-1.05)^{\dagger}$ & $1.02(1.00-1.05)^{\dagger}$ \\
\hline
\end{tabular}

In the dementia group, older age, unemployment, low IADL performance, and more neuropsychiatric symptoms were likely to have increased risk of accidental death in the univariate model. In multivariate analysis, advanced age (HR 2.21, 95\% CI 1.04-4.68) and decreased activity of daily living (HR 1.06, 95\% CI 1.01-1.08) were associated with a higher risk of accidental death. Unemployment increased the risk of both suicide (HR 3.71, 95\% CI 1.54-8.95) and accidental death (HR 2.09, 95\% CI 1.20-3.63).

In the MCI group, advanced age (HR 3.63, 95\% CI 1.12-11.79), decreased activity of daily living (HR 1.08, 95\% CI 1.03-1.12), and more neuropsychiatric symptoms (HR 1.02, 95\% CI 1.00-1.05) were associated with a higher risk of accidental death in the multivariate model. Interestingly, as the duration of education increased, the risk of suicide (HR 0.90, 95\% CI 0.81-0.99) decreased, while that of accidental death (HR 1.01, 95\% CI 1.00-1.13) slightly increased.

\section{Discussion}

To our best knowledge, this is the first cohort study on mortality according to suicide and accidental death that considers the characteristics of each cause of death in patients with cognitive impairment. It is also noteworthy that by separately performing analysis for mortality of the MCI group, we were able to better understand the characteristics of suicide and accidental death in early or milder forms of cognitive impairment. Along with follow-up data for a decade related to causes of death, our findings would contribute toward broadening knowledge of the underlying determinants of suicide and accidental death in patients with cognitive impairment.

According to our study, the risk of suicide among patients with cognitive impairment did not increase significantly, which is consistent with the findings of most previous studies [27-29]. Even though there have been several efforts to predict the clinical factors of suicidal death in people with dementia, most participants were either psychiatric inpatients or had severe medical comorbidity [13, 30, 31], which made it difficult to ascertain the true risks of suicide itself in those with cognitive impairment. Furthermore, suicide in elderly patients with cognitive impairment did not demonstrate the usual risk factors for elderly suicide, such as the male gender or advancing age [32]. This suggests that the 
nature of suicide in elderly patients with cognitive impairment is somewhat different from the elderly without cognitive impairment.

However, among the suicide cases, cognitive limitation seems to be a hindrance to the implementation of a suicidal plan. Our study shows that the suicidal death group was younger and had better cognitive function, and their mean time from registry to death was shorter. This leads us to believe that they may have had less cognitive impairment and more preserved insight at the time death. This supports the findings of several previous studies $[8,33]$ that report better cognitive function enabling suicidal execution, and retained insight into the disease may increase the risk of dying by suicide in dementia patients [11]. As an interesting comparison, cancer patients were more likely to die from non-cancer causes than from cancer itself [34]. Recent studies consistently reported that the risk of suicide among cancer patients is higher than that of the general population and younger cancer patients within the first year of diagnosis had higher suicide death $[35,36]$. Both dementia and cancer patients with better insight may possibly become frustrated due to their awareness of functional impairment or loss of autonomy. Therefore, close observation and suicide prevention strategies have to be aimed at such patients.

On the other hand, the risk of accidental death tends to increase as CDR and the severity of cognitive impairment increase in both dementia and MCI groups, which might be due to more impaired locomotor activity, such as reaction time, coordination, or walking as well as deterioration of situational awareness and short-term memory. This finding suggests that the cause of death may vary according to the severity of neurocognitive impairment in patients with cognitive impairment.

Older age was a consistent risk factor for accidental death in both dementia and MCI groups. It is noteworthy that the mortality rate of accidental death is more than 3.5 folds in MCI by 1 year. Aging seems to be an independent risk factor of accidental death in people with a cognitive impairment; therefore, we should be aware of the potential risk of accidents beginning from the early stages of the disease. Interestingly, current unemployment state increased the risk of both suicide and accidental death in dementia patients. Leaving employment is reported to be a risk factor of suicide [37]. Furthermore, patients with advanced cognitive impairment symptoms may be unable to continue working; hence, unemployment can be one of the predictors of decreased functional ability, which may subsequently increase the risk of accidents. According to the subtypes of cognitive impairment, both Alzheimer's disease and vascular dementia demonstrated high SMR for accidental death. Patients with vascular dementia had over two folds of the risk of accidental death, which could be due to cardiovascular risk or medical comorbidity of vascular dementia itself.

As we had expected, suicide and accidental deaths are the primary issues that need to be considered to reduce premature mortality in elderly patients with cognitive impairment and are related to several clinical risk factors.

There are a few limitations of this study. First, as we included clinical variables at the time of study registration, it enabled clinicians to screen mortality risk among patients with cognitive impairment initially, but there was a lack of timely details of death-related events. For example, a patient may have had depression or medical comorbidities that had an independent effect on his or her mortality at the time of death. Second, the small number of suicidal deaths limited the study of risk factors of death. Further research should focus on elucidating the temporal relationship between each type of death and dementia-specific symptoms, in addition to suicidal ideation or attempts, self-mutilating behaviors, and non-fatal accidents.

\section{Conclusions}

The risk of death by suicide did not increase significantly among patients with cognitive impairment. However, the risk of accidental death was higher, especially in older patients and those with severe forms of cognitive impairment. Improved awareness and understanding of patients' mortality are needed at the onset of cognitive evaluation in order to develop better risk-management strategies.

\section{Abbreviations \\ CDR: Clinical Dementia Rating Scale; CREDOS: Clinical Research Center for Dementia of Korea; K-MMSE: Korean Mini-Mental State Examination; $\mathrm{MCl}$ : Mild cognitive impairment; NPI: Neuropsychiatric inventory; S- IADL: Seoul Instrumental Activity of Daily Living; SMR: Standardized morality ratio}

\section{Acknowledgements}

We would like to acknowledge the Ministry of Health and Welfare, Republic of Korea for their support of data collection.

\section{Funding}

This work was supported by the Korea Mental Health R\&D project, Ministry of Health and Welfare, Republic of Korea [HM15C1072, HL19C0018]

\section{Availability of data and materials}

The datasets generated and analyzed during the current study are not publicly available because we are preparing an additional manuscript. However, they are available upon the reasonable request to corresponding author.

\section{Authors' contributions}

$J H A$ participated in the study design, conception, data acquisition, and data analysis; wrote the first manuscript draft; and revised the new drafts from coauthors. KEL participated in the design, conceptualized the study, and revised the manuscript. HJJ, SJS, and SYK developed the questionnaire, directed the data acquisition, and participated in the study design and conceptualization. JPH participated in study design and conception, data acquisition, 
manuscript drafting, and funding acquisition. All authors read and approved the final manuscript

\section{Ethics approval and consent to participate}

Written informed consent was obtained from all participants before conducting self-questionnaires and face-to-face interviews. This study was conducted with the approval of institutional review board, the Samsung Seoul Hospital Clinical Research Committee. (IRB No.2016-05-014)

\section{Consent for publication}

Not applicable.

\section{Competing interests}

The authors declare that they have no competing interests.

\section{Publisher's Note}

Springer Nature remains neutral with regard to jurisdictional claims in published maps and institutional affiliations.

\section{Author details}

${ }^{1}$ Department of Psychiatry, Samsung Medical Center, Sungkyunkwan University School of Medicine, 81 Irwon-ro Gangnam-gu, Seoul 06351, South Korea. ${ }^{2}$ Department of Psychiatry, Ajou University School of Medicine, Suwon, South Korea. ${ }^{3}$ Department of Psychiatry, Asan Medical Center, Ulsan University School of Medicine, Seoul, South Korea.

Received: 7 January 2019 Accepted: 29 March 2019

Published online: 11 April 2019

\section{References}

1. WHO and Alzheimer's Disease International. Dementia: a public health priority. Geneva: World Health Organization; 2012. p. 404

2. Rizzi L, Rosset I, Roriz-Cruz M. Global epidemiology of dementia: Alzheimer's and vascular types. Biomed Res Int. 2014;2014:908915.

3. Prince $M$, Acosta $D$, Ferri $C P$, Guerra $M$, Huang $Y$, Rodriguez JJL, et al. Dementia incidence and mortality in middle-income countries, and associations with indicators of cognitive reserve: a 10/66 Dementia Research Group population-based cohort study. Lancet. 2012;380:50-8.

4. Shah A, Bhat R, Zarate-Escudero S, DeLeo D, Erlangsen A. Suicide rates in five-year age-bands after the age of 60 years: the international landscape. Aging Ment Health. 2016;20:131-8.

5. Office KNS. Annual report on the causes of death statistics. Statistics Korea, Government Complex-Daejeon, 189 Cheongsa-ro, Seo-gu, Daejeon 35208, Republic of Korea. 2016.

6. Suicide WP. A global imperative. Geneva: World Health Organization; 2014

7. Conwell Y, Duberstein PR, Caine ED. Risk factors for suicide in later life. Bio Psychiatry. 2002;52:193-204.

8. Erlangsen A, Zarit SH, Conwell Y. Hospital-diagnosed dementia and suicide: a longitudinal study using prospective, nationwide register data. Am J Geriatr Psychiatry. 2008;16:220-8.

9. Cipriani G, Vedovello M, Lucetti C, Di Fiorino A, Nuti A. Dementia and suicidal behavior. Aggress Violent Behav. 2013;18:656-9.

10. Draper B, MacCuspie-Moore C, Brodaty H. Suicidal ideation and the 'wish to die' in dementia patients: the role of depression. Age Ageing. 1998;27:503-7.

11. Lim WS, Rubin EH, Coats M, Morris JC. Early-stage Alzheimer disease represents increased suicidal risk in relation to later stages. Alzheimer Dis Assoc Disord. 2005;19:214-9.

12. Vega U, Kishikawa Y, Ricanati E, Friedland RP. Suicide and Alzheimer disease. Am J Geriatr Psychiatry. 2002:10:484-5.

13. Seyfried LS, Kales HC, Ignacio RV, Conwell Y, Valenstein M. Predictors of suicide in patients with dementia. Alzheimers Dement. 2011:7:567-73.

14. Crump C, Sundquist K, Winkleby MA, Sundquist J. Mental disorders and risk of accidental death. Br J Psychiatry. 2013;203:297-302.

15. Park HK, Na DL, Han S-H, Kim J-Y, Cheong H-K, Kim SY, et al. Clinical characteristics of a nationwide hospital-based registry of mild-to-moderate Alzheimer's disease patients in Korea: a CREDOS (Clinical Research Center for Dementia of South Korea) study. J Korean Med Sci. 2011;26:1219-26.

16. McKhann G, Drachman D, Folstein M, Katzman R, Price D, Stadlan EM. Clinical diagnosis of Alzheimer's disease: report of the NINCDS-ADRDA Work Group under the auspices of Department of Health and Human Services Task Force on Alzheimer's Disease. Neurology. 1984;34:939-44.
17. Román GC, Tatemichi TK, Erkinjuntti T, Cummings J, Masdeu J, Garcia J, et al. Vascular dementia: diagnostic criteria for research studies: report of the NINDS-AIREN International Workshop. Neurology. 1993;43:250.

18. Hachinski VC, lliff LD, Zilhka E, Du Boulay GH, McAllister VL, Marshall J, et al. Cerebral blood flow in dementia. Arch Neurol. 1975;32:632-7.

19. McKeith IG, Galasko D, Kosaka K, Perry E, Dickson D, Hansen L, et al. Consensus guidelines for the clinical and pathologic diagnosis of dementia with Lewy bodies (DLB): report of the consortium on DLB international workshop. Neurology. 1996:47:1113-24.

20. Englund B, Brun A, Gustafson L, Passant U, Mann D, Neary D, et al. Clinical and neuropathological criteria for frontotemporal dementia. J Neurol Neurosurg Psychiatry. 1994;57:416-8.

21. Association AP. Diagnostic and statistical manual of mental disorders. 4th ed. Washington DC: American Psychiatric Association; 1994.

22. Ahn H-J, Chin J, Park A, Lee BH, Suh MK, Seo SW, et al. Seoul Neuropsychological Screening Battery-Dementia Version (SNSB-D): a useful tool for assessing and monitoring cognitive impairments in dementia patients. J Korean Med Sci. 2010;25:1071-6.

23. Morris JC. The Clinical Dementia Rating (CDR): current version and scoring rules. Neurology. 1993;43:2412-4.

24. Kang Y, Na DL, Hahn S. A validity study on the Korean Mini-Mental State Examination (K-MMSE) in dementia patients. J Korean Neurol Assoc. 1997:15:300-8.

25. Ku HM, Kim JH, Kwon EJ, Kim SH, Lee HS, Ko HJ, et al. A study on the reliability and validity of Seoul-Instrumental Activities of Daily Living (SIADL). J Korean Neuropsychiatr Assoc. 2004;43:189-99.

26. Choi SH, Na DL, Kwon HM, Yoon SJ, Jeong JH, Ha CK. The Korean version of the neuropsychiatric inventory: a scoring tool for neuropsychiatric disturbance in dementia patients. J Korean Med Sci. 2000;15:609-15.

27. Harris EC, Barraclough B. Suicide as an outcome for mental disorders. A meta-analysis. Br J Psychiatry. 1997;170:205-28.

28. Purandare N, Voshaar RCO, Rodway C, Bickley H, Burns A, Kapur N. Suicide in dementia: 9-year national clinical survey in England and Wales. $\mathrm{Br} \mathrm{J}$ Psychiatry. 2009;194:175-80.

29. Wiktorsson S, Runeson B, Skoog I, Östling S, Waern M. Attempted suicide in the elderly: characteristics of suicide attempters 70 years and older and a general population comparison group. Am J Geriatr Psychiatry. 2010;18:57-67.

30. Harwood D, Hawton K, Hope T, Jacoby R. Psychiatric disorder and personality factors associated with suicide in older people: a descriptive and case-control study. Int J Geriatr Psychiatry. 2001;16:155-65.

31. VanCott AC, Cramer JA, Copeland LA, Zeber JE, Steinman MA, Dersh JJ, et al. Suicide-related behaviors in older patients with new anti-epileptic drug use: data from the VA hospital system. BMC Med. 2010;8:4.

32. Conwell Y. Suicide among elderly persons. Psychiatric services (Washington, DC). 1995:46:563-4.

33. Ready RE, Ott BR, Grace J, Cahn-Weiner DA. Apathy and executive dysfunction in mild cognitive impairment and Alzheimer disease. Am J Geriatr Psychiatry. 2003;11:222-8.

34. Zaorsky NG, Churilla TM, Egleston BL, Fisher SG, Ridge JA, Horwitz EM, et al. Causes of death among cancer patients. Ann Oncol. 2017;28:400-7.

35. Zaorsky NG, Zhang Y, Tuanquin L, Bluethmann SM, Park HS, Chinchilli VM. Suicide among cancer patients. Nat Commun. 2019;10:207.

36. Saad AM, Gad MM, Al-Husseini MJ, AlKhayat MA, Rachid A, Alfaar AS, et al. Suicidal death within a year of a cancer diagnosis: a population-based study. Cancer. 2019;125:972-9.

37. Blakely TA, Collings SC, Atkinson J. Unemployment and suicide. Evidence for a causal association? J Epidemiol Community Health. 2003;57:594-600.

Ready to submit your research? Choose BMC and benefit from:

- fast, convenient online submission

- thorough peer review by experienced researchers in your field

- rapid publication on acceptance

- support for research data, including large and complex data types

- gold Open Access which fosters wider collaboration and increased citations

- maximum visibility for your research: over $100 \mathrm{M}$ website views per year

At $\mathrm{BMC}$, research is always in progress.

Learn more biomedcentral.com/submissions 